Original Article

\title{
Inhibition of chromosomal region maintenance 1 suppresses the migration and invasion of glioma cells via inactivation of the STAT3/MMP2 signaling pathway
}

\author{
Qianqian Shan ${ }^{1, \#}$, Shengsheng Li ${ }^{1, \#}$, Qiyu Cao ${ }^{1, \#}$, Chenglong Yue ${ }^{1}$, Mingshan Niu ${ }^{1,2}$, Xiangyu Chen ${ }^{1}$, Lin Shi ${ }^{1}$, Huan Li ${ }^{1}$, \\ Shangfeng $\mathrm{Gao}^{1,3}$, Jun Liang ${ }^{3}$, Rutong $\mathrm{Yu}^{1,3, *}$, and Xuejiao $\mathrm{Liu}^{1,3, *}$ \\ ${ }^{1}$ Insititute of Nervous System Diseases, The Affiliated Hospital of Xuzhou Medical University, Xuzhou Medical University, ${ }^{2}$ Jiangsu Key Laboratory of Bone Marrow \\ Stem Cell, Xuzhou Medical University, ${ }^{3}$ Department of Neurosurgery, The Affiliated Hospital of Xuzhou Medical University, Xuzhou, Jiangsu 221002, China
}

\section{ARTICLE INFO}

Received July 13, 2019

Revised December 19, 2019

Accepted December 20, 2019

\section{*Correspondence \\ Xuejiao Liu \\ E-mail: liuxuejiao0923@126.com \\ Rutong Yu \\ E-mail:yu.rutong@163.com}

\section{Key Words}

Glioma

Invasion

Migration

S109

STAT3/MMP2 signaling

\#These authors contributed equally to this work.

\begin{abstract}
Chromosomal region maintenance 1 (CRM1) is associated with an adverse prognosis in glioma. We previously reported that CRM1 inhibition suppressed glioma cell proliferation both in vitro and in vivo. In this study, we investigated the role of CRM1 in the migration and invasion of glioma cells. S109, a novel reversible selective inhibitor of CRM1, was used to treat Human glioma U87 and U251 cells. Cell migration and invasion were evaluated by wound-healing and transwell invasion assays. The results showed that $\mathrm{S} 109$ significantly inhibited the migration and invasion of U87 and U251 cells. However, mutation of Cys528 in CRM1 abolished the inhibitory activity of S109 in glioma cells. Furthermore, we found that S109 treatment decreased the expression level and activity of MMP2 and reduced the level of phosphorylated STAT3 but not total STAT3. Therefore, the inhibition of migration and invasion induced by S109 may be associated with the downregulation of MMP2 activity and expression, and inactivation of the STAT3 signaling pathway. These results support our previous conclusion that inhibition of CRM1 is an attractive strategy for the treatment of glioma.
\end{abstract}

\section{INTRODUCTION}

Glioblastoma (GBM) is the most common and aggressive brain tumor and constitutes approximately $54 \%$ of all gliomas, frequently infiltrating into surrounding brain tissues owing to its high migration and invasion characteristics [1,2]. Despite advances in diagnostics and clinical therapeutic regimens, the median survival for GBM patients is approximately 15 months $[3,4]$. Therefore, there is a critical need to understand the molecular mechanisms of glioma cell migration and invasion to guide the development of new therapeutic strategies.
Substantial amounts of data have confirmed that the development of tumors is related to the abnormal localization and dysfunction of many cellular proteins $[5,6]$. XPO1/chromosomal region maintenance 1 (CRM1) plays a prominent role in the regulation of nuclear protein export [7], and overexpression of CRM1 has been reported in pancreatic, esophageal, osteosarcoma, ovarian, and gastric tumors, as well as in gliomas [8-13]. Thus, the nuclear exporter protein CRM1 may act as a novel potential therapeutic target for these deadly diseases. A large number of CRM1 inhibitors were discovered. Previous reports have shown that CRM1 specific inhibitors (such as Laptomycin B [LMB], KPT-185,

\section{(i) (5)}

This is an Open Access article distributed under the terms of the Creative Commons Attribution Non-Commercial License, which permits unrestricted non-commercial use, distribution, and reproduction in any medium, provided the original work is properly cited. Copyright $\odot$ Korean J Physiol Pharmacol, pISSN 1226-4512, elSSN 2093-3827
Author contributions: X.L. and R.Y. designed this study. Q.S., S.L., and Q.C. performed the main experimental procedures. C.Y., M.N., X.C., L.S., and H.L. carried out partial experiments. S.G. and J.L. performed the statistical analysis. X.L. and S.L. wrote this manuscript. All the authors read and approved the final manuscript. 
-330 and so on) modify CRM1 at the reactive cysteine 528 site and abrogate the interaction between CRM1 and its cargo protein $[14,15]$. However, most of the currently available CRM1 inhibitors irreversibly bind to CRM1 and exhibit a relatively unfavorable drug tolerability profile [16]. Accordingly, a safer, more effective, and less toxic CRM1 inhibitor is urgently needed. Our previous study showed that the novel reversible CRM1 inhibitor S109 suppressed the proliferation of glioma cells both in vitro and in vivo [12]. However, the role of CRM1 in the migration and invasion of tumor cells remains unclear.

The signal transducer and activator of transcription 3 (STAT3) is a transcription factor that has been identified in various types of tumors, including breast, pancreatic, lung, prostatic, and brain cancers $[17,18]$. Activation of STAT3 is thought to play an important role in several features of malignant neoplasia including tumor cell survival, metastasis, and resistance to chemotherapy [19-22]. Evidence strongly suggests that STAT3 is an important oncogenic driver of GBM, and it has been shown that STAT3 inhibition in glioma can decrease the capacity for cell migration and invasion through reducing the activity and expression of MMP2 [23]. Moreover, siRNA-mediated silencing of STAT3 identifiably suppressed the chemo-responsiveness and migratory ability of glioma stem cells, and STAT3 plays an important role in maintaining self-renewal of glioma stem cells [24]. Given the apparent role of STAT3 in the genesis and progression of glioma, inactivation of the STAT3 signaling pathway may be an effective treatment strategy for these lethal diseases.

In this study, we investigated the effects of the CRM1 inhibitor S109 on migration and invasion of glioma cells. Results showed that S109 suppressed the invasion and migration of glioma cells partly due to the inactivation of the STAT3/MMP2 signaling pathway. Furthermore, our study provides insights into the applicability of using S109 as a potential targeted drug in gliomas.

\section{METHODS}

\section{Cell culture and reagents}

The human glioma cell line U251 was purchased from the Shanghai Cell Bank, Chinese Academy of Sciences. U87 cells, glioblastoma of unknown origin (catalog number: ATCC HTB14), were derived from ATCC. These cells were cultured in DMEM supplemented with 10\% FBS. These cell lines were grown in a humidified incubator containing $5 \% \mathrm{CO}_{2}$ at $37^{\circ} \mathrm{C}$. Primary antibodies against CRM1 (sc-74454) and actin (sc-58673) were obtained from Santa Cruz Biotechnology (Santa Cruz, CA, USA). The antibodies to STAT3 (9139s), p-STAT3 (9145s), and MMP2 (13132s) were purchased from Cell Signaling Technology (Beverly, MA, USA). The S109 compound was synthesized by the Suzhou Komanda Drug Development Company. S109 was dissolved in DMSO to create a $10 \mathrm{mM}$ solution, which was diluted to different concentrations of medium before use.

\section{Wound-healing assay}

The migration behavior of glioma cells was evaluated using the wound-healing assay, according to our previous report $[25,26]$. U87 and U251 cells were seeded in 6-well plates and allowed to attach overnight. A rectangular lesion was created by using a plastic pipette tip, and cells were then incubated in serum-free media. The cells were incubated in serum-free media and treated with either 0.1\% DMSO or S109. After incubation for 24 h or 48 $\mathrm{h}$, cell migration into the wounded areas was observed and photographed using an inverted microscope. The experiments were independently performed three times.

\section{Transwell invasion assay}

Cell invasion assay was performed using a transwell system as described previously $[27,28]$. Culture inserts were coated with Matrigel and placed into the wells of 24-well culture plates. U87 and U251 cells were treated with either 0.1\% DMSO or S109 in serum-free media and added to the top chamber. In the lower chamber, DMEM media containing 10\% FBS was added. After $30 \mathrm{~h}$ of incubation, the noninvasive cells were removed from the upper chamber, the filters were fixed in $4 \%$ methanol for $20 \mathrm{~min}$, and then stained with a $0.1 \%$ crystal violet solution for $30 \mathrm{~min}$. The invading cells on the filter were counted from six randomly selected fields. The experiments were performed at least three times.

\section{Western blotting}

U87 and U251 cells were treated with variable concentrations of S109. The supernatants were collected by centrifugation at 13,000 $\mathrm{g}$ for $30 \mathrm{~min}$ and stored at $-20^{\circ} \mathrm{C}$. The total protein extracts from treated or untreated cells were used to western blot analysis within three days as described elsewhere [29-31]. The expression patterns of STAT3, p-STAT3, MMP2 were detected using specific antibodies, and $\beta$-actin were used as the loading control (all diluted to $1: 1,000)$.

\section{Gelatin zymography assay}

The activity of MMP2 was assessed by gelatin zymography assay. The cells were seeded in 12-well culture plates and cultured for $24 \mathrm{~h}$ at $37^{\circ} \mathrm{C}$. The cells were washed twice with PBS and incubated for an additional $24 \mathrm{~h}$ in serum-free medium supplemented with different concentrations of S109. Then, in the SDS loading buffer, media was harvested, centrifuged and resuspended without the use of $\beta$-mercaptoethanol. All samples were analyzed by $10 \%$ SDS-PAGE (containing $0.2 \%$ gelatin). Gels were washed in $2.5 \%$ Triton X-100 three times to remove SDS and then incubated 
overnight in reaction buffer. Subsequently, gels were stained with $0.25 \%$ Coomassie Brilliant blue R-250 and destained with $40 \%$ methanol and $10 \%$ acetic acid. The gelatinolytic activity of MMP2 in the gel was detected as clear white bands on a dark background.

\section{Establishment of CRM1-wild-type (WT) and CRM1- $C 528 S$ stable cell lines}

Human CRM1 wild-type and C528S mutant genes were cloned into pWPXLD lentiviral expression vector containing a sequence coding for a flag tag. Then the constructed plasmids were sequenced. The viruses were produced in 293FT cells and used to infect U87 glioma cells according to our previous literature [12]. After $48 \mathrm{~h}$ infection, the cells were continuously cultured in medium containing $2.5 \mu \mathrm{g} / \mathrm{ml}$ puromycin. The surviving cells were cultured into cell lines stably expressing CRM1-WT or CRM1C528S.

\section{Statistical analysis}

The statistical analyses were performed using the GraphPad Prism 5 software package (GraphPad Software, Inc., San Diego, CA, USA). Each experiment was repeated independently at least three times. Values are expressed as means \pm standard error of the mean. The selected chart represents results from one of the repeated experiments. Comparisons of the mean values between the control and treated groups were performed using Students ttest. p-values $<0.05$ were considered statistically significant.

\section{RESULTS}

\section{Effects of S109 on the migration of glioma cells}

To investigate the influence of $\mathrm{S} 109$ on the migration and invasion of glioma cells, wound-healing and transwell invasion assays were performed. Compared to control cells, the number of migratory U87 cells was decreased to $42.7 \%, 34.5 \%$, and $18.8 \%$ at 24 $\mathrm{h}$ and $52.6 \%, 30.3 \%$, and $15.3 \%$ at $48 \mathrm{~h}$ in response to treatment with $0.5 \mu \mathrm{M}, 1 \mu \mathrm{M}$, and $2 \mu \mathrm{M}$ S109, respectively (Fig. 1). Similar results were obtained in U251 cells. After $24 \mathrm{~h}$ incubation, the average number of migratory U251 cells was decreased to $61.9 \%$, $46.9 \%$, and $30.0 \%$, and at $48 \mathrm{~h}$ these numbers were decreased to $61.5 \%, 49.7 \%$, and $32.7 \%$ following treatment with $0.5 \mu \mathrm{M}, 1 \mu \mathrm{M}$, and $2 \mu \mathrm{M} \mathrm{S109}$, respectively. To exclude the possibility that the concentrations of S109 used in the migration assay had no obvious cytotoxic effect on U87 and U251 cells, we used the CCK8 assay to assess the effect of $S 109(0-2 \mu \mathrm{M})$ on cell viability after 24 $\mathrm{h}$ or $48 \mathrm{~h}$. We found that the lower doses of $\mathrm{S} 109(0-2 \mu \mathrm{M})$ had no obvious effect on cell viability after $24 \mathrm{~h}$ and $48 \mathrm{~h}$ (Supplementary Fig. 1, Table 1). Our results demonstrated that S109 significantly inhibited the migration of glioma cells.

\section{Effects of S109 on the invasion of glioma cells}

Next, we further investigated the effects of S109 on human glioma cell invasion via transwell invasion assay. The results showed that S109 induced a dose-dependent reduction in invasive cell numbers with increasing concentrations of S109. Compared with the control group, the mean invasive U87 cell number was reduced to $60.2 \%, 49.3 \%$, and $13 \%$ at $0.25 \mu \mathrm{M}, 0.5 \mu \mathrm{M}$, and 1 $\mu \mathrm{M}$ S109 treatment, respectively. Similarly, the exposure of U251 cells to $0.25 \mu \mathrm{M}, 0.5 \mu \mathrm{M}$, and $1 \mu \mathrm{M}$ S109 reduced invasion rate
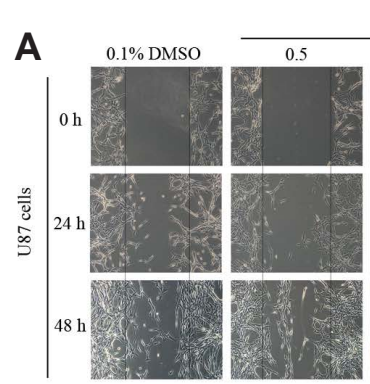

$\mathrm{S} 109(\mu \mathrm{M})$
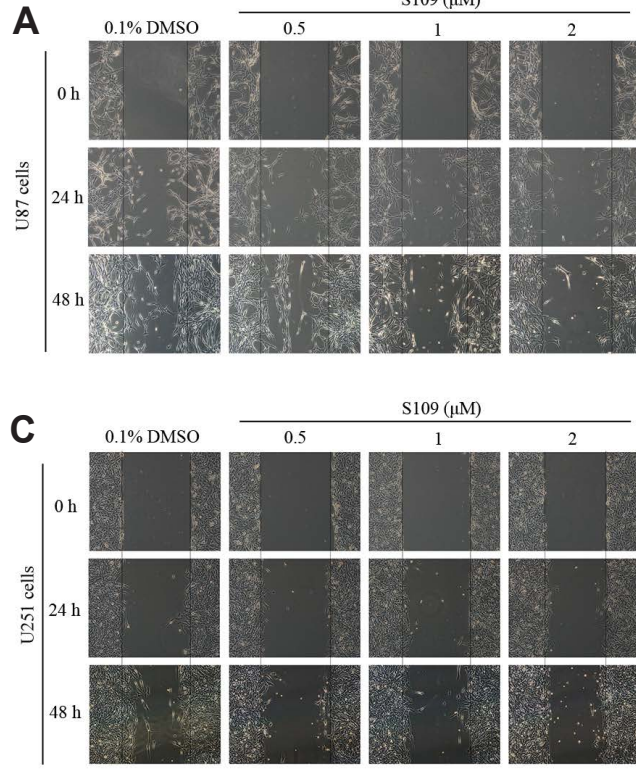

$\mathrm{S} 109(\mu \mathrm{M})$
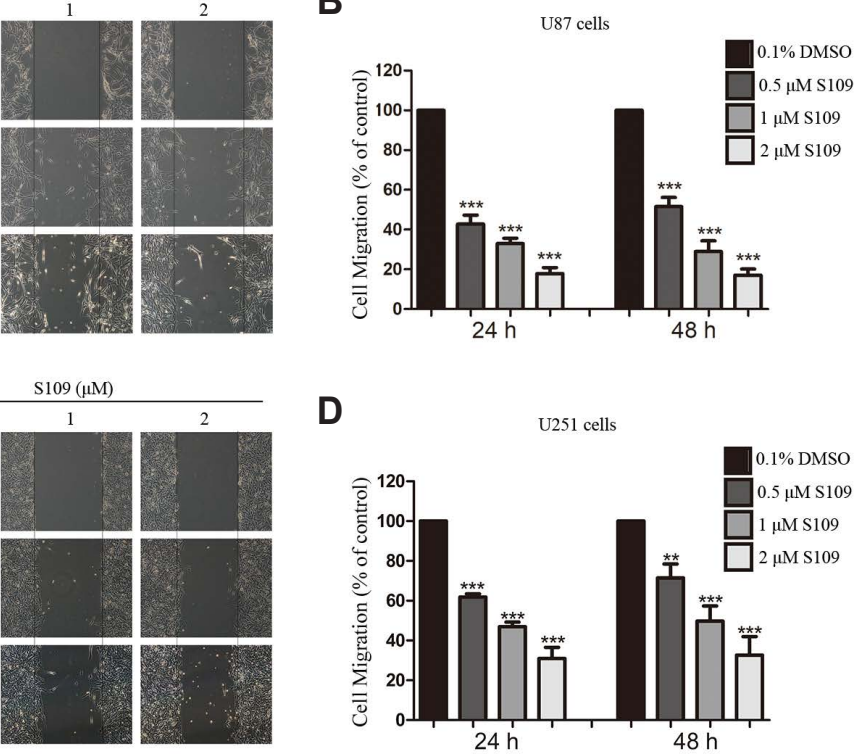

Fig. 1. S109 suppressed the migration of U87 and U251 cells. (A, C) U87 and U251 cells were treated with vehicle or various concentrations of S109 for $24 \mathrm{~h}$ and $48 \mathrm{~h}$. Wound-healing assay was then performed to evaluate cell migratory capacity. (B, D) Quantitative analysis of migratory cell numbers. The number of migratory cells was counted and then normalized to that of the control group. The data are presented as the means \pm standard error of the mean from three independent experiments, ${ }^{* *} p<0.01$, *** $p<0.001$. 
to $64.8 \%, 49.3 \%$, and $16.0 \%$, respectively (Fig. 2). Taken together, these data imply that $\$ 109$ effectively inhibited the migration and invasion of glioma cells.

\section{S109 inhibits the expression and activity of MMP2 by blocking STAT3 signaling}

MMP2 and MMP9 are vital enzymes involved in the degradation of the extracellular matrix (ECM) and the components of the basement membrane [32]. Given that the activity of MMP2 is considered to be a vital factor in tumor invasion, we first evaluated the effects of S109 on the activity and expression of MMP2 in U87 and U251 cells via gelatin zymography assay and Western blot analysis, respectively. As illustrated in Fig. 3A and B, S109 reduced the activity of MMP2 in U87 and U251 cells in a dosedependent manner. Next, we further evaluated the expression of MMP2 after treatment with S109. The data indicated that treatment with increasing concentrations of S109 induced a significant decrease in the expression level of MMP2 in U87 and U251 cells (Fig. 3C-F).

Previous studies have indicated that MMP2 gene expression is transcriptionally regulated by various transcription factors, including STAT3 [33]. The activity of STAT3 is necessary for invasion in gliomas. Down-regulation of STAT3 reduces invasive activity via suppressing the expression of MMP2 in gliomas $[34,35]$. Hence, we further investigated the effects of S109 on the activity and expression of STAT3 in U87 and U251 cells, and the results are shown in Fig. 3G and I. The level of phosphorylated STAT3 but not the total STAT3 was markedly decreased in a dose-dependent manner after treatment with S109. The above data suggested that S109 might inhibit the expression and activity of MMP2 by inactivating STAT3 signaling.

\section{The CRM1 Cys528 mutation abrogates the inhibition of glioma cell migration and invasion by $\mathrm{S} 109$}

The Cys528 residue in the cargo-binding pocket of CRM1 is essential for the inhibitory effect of the CRM1 inhibitor [36]. Our previous study demonstrated that $\mathrm{S} 109$ possesses potent antiproliferative activity through selectively binding to the Cys528 residue of CRM1 in gliomas [12]. In the present study, previously constructed U87 cell lines stably expressing CRM1-WT and CRM1-C528S were used to further investigate whether S109 inhibits the invasion and migration of glioma cells by specifically inhibiting CRM1 [12]. The identification of CRM1-WT and CRM1-C528S stable cell lines is shown in Supplementary Fig. 2. The results of wound-healing and transwell invasion assays suggested that S109 treatment markedly attenuated the migratory and invasive ability of glioma cells that express the wild-type CRM1. However, the inhibitory effect of S109 on the migration and invasion of glioma cells was nearly abolished in the cells expressing the Cys528 mutant CRM1 (Fig. 4A-D). Subsequently, we further examined the effect of S109 on p-STAT3 expression in CRM1-WT and CRM1-C528S expressing cells. We found that S109 inhibited the phosphorylation of STAT3. In contrast, the CRM1 Cys528 mutation abrogated the inhibition of p-STAT3 expression induced by S109 treatment. The results are shown in Fig. 4E. These findings further provide evidence suggesting that S109 can inhibit glioma cell migration and invasion through selectively binding the Cys528 residue of CRM1.

\section{DISCUSSION}

GBM is the most common and the most devastating primary
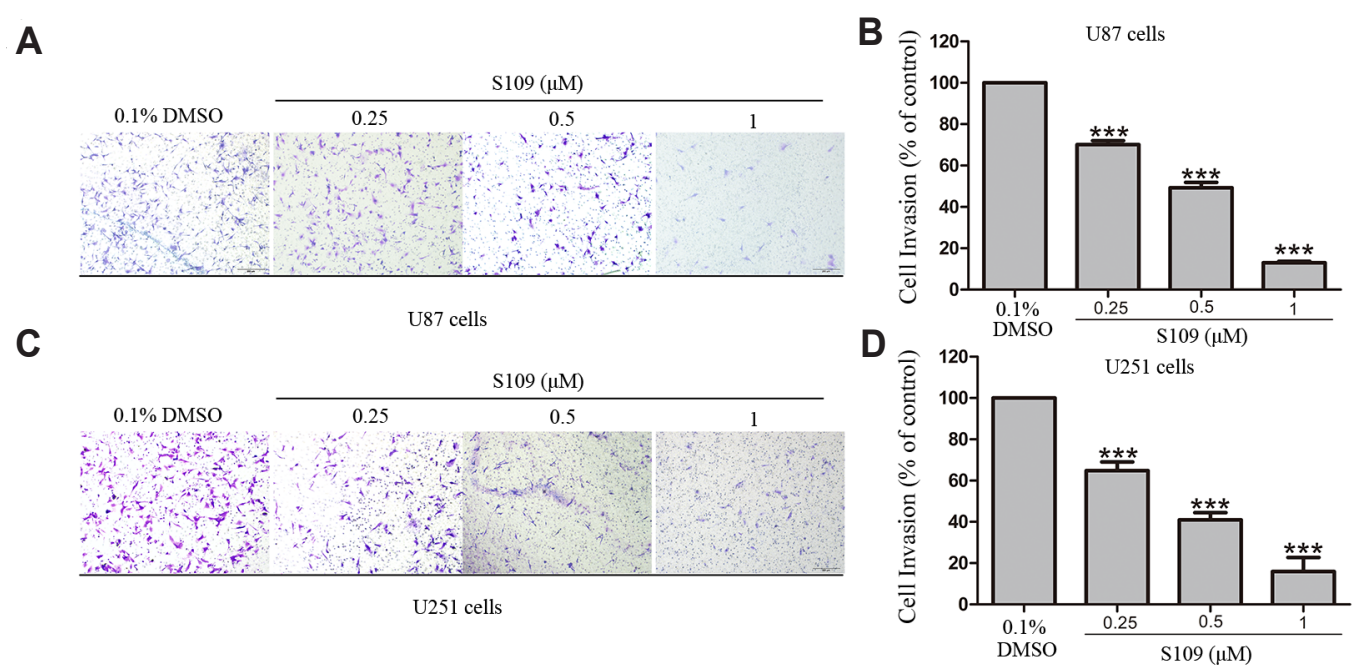

Fig. 2. S109 treatment decreased the invasive ability of U87 and U251 cells. (A, C) U87 and U251 cells were treated with vehicle or S109 (0.25 $\mu M$, $0.5 \mu \mathrm{M}$, and $1.0 \mu \mathrm{M})$ for $30 \mathrm{~h}$, and then cell invasion was assessed by transwell invasion assay. The invasive cells were stained with a $0.1 \%$ crystal violet solution for $30 \mathrm{~min}$. (B, D) Quantitation of numbers of cells that invaded through the filter. The number of invading cells was counted and normalized to the control group. The data are expressed as the means \pm standard error of the mean from three independent experiments, ${ }^{* * *} \mathrm{p}<0.001$. 
A

U87 cells

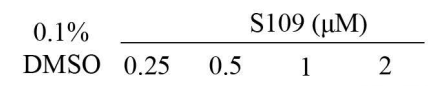

MMP2
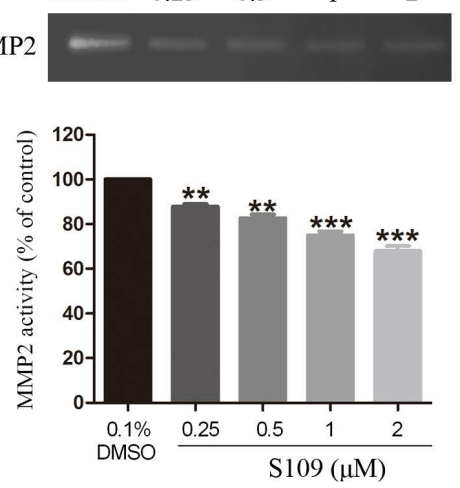

C

U87 cells

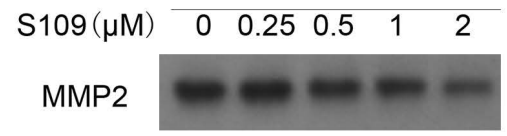

Actin

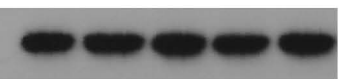

E

U251 cells

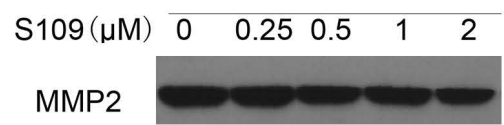

Actin

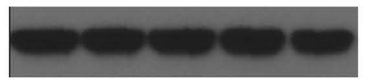

G

U87 cells

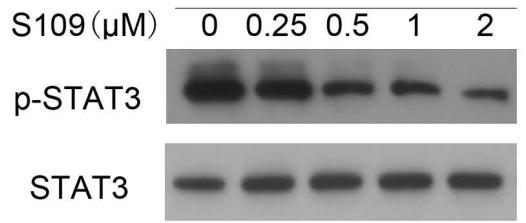

Actin

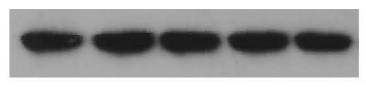

I

U251 cells

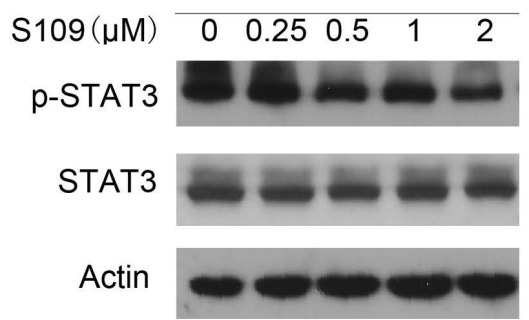

B

U251 cells

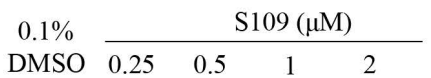

MMP2
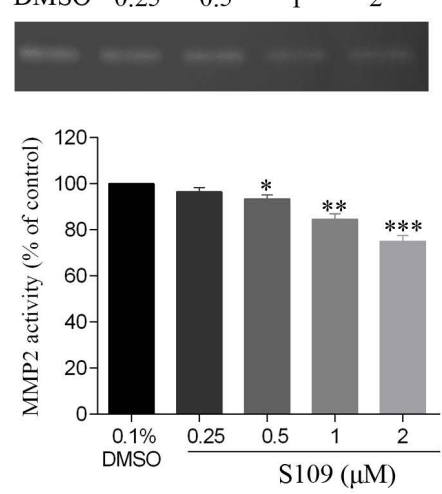

D

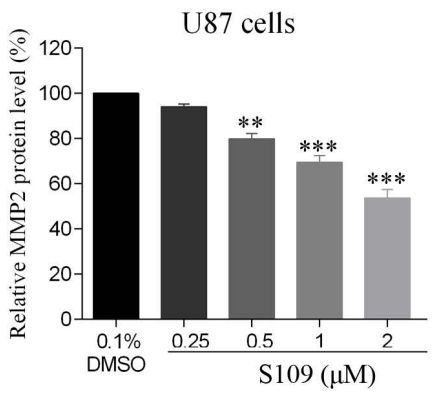

$\mathbf{F}$

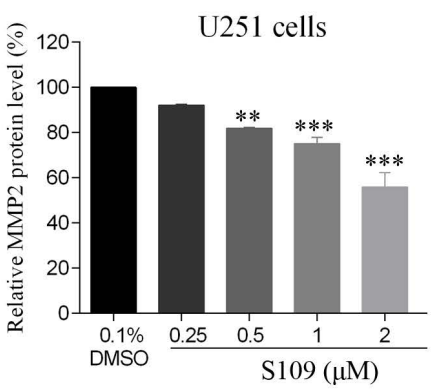

H

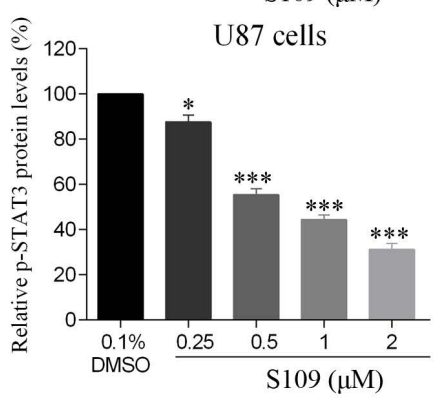

J

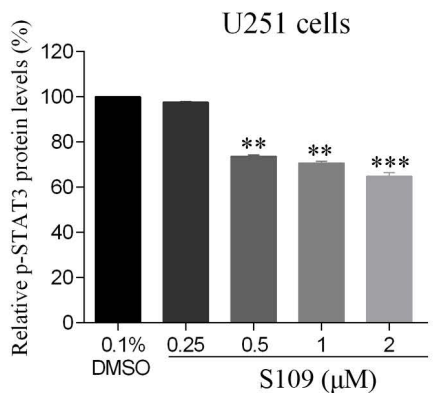

Fig. 3. S109 inhibited the activity and expression of MMP2 via inactivation of STAT3 signaling. (A, B) Representative picture and quantitative MMP2 activity of gelatin zymography assay. Cells were treated with $\mathrm{S} 109$ at the indicated concentrations, and then the gelatin zymography assay was performed. (C-F) The effects of S109 on MMP2 expression by Western blot analysis. (G-J) Phosphorylated STAT3 and total STAT3 expression were examined in U87 and U251 cells treated with S109. All data presented here are the means \pm standard error of the mean from three independent experiments, ${ }^{*} p<0.05,{ }^{* *} p<0.01,{ }^{* * *} p<$ 0.001 . 
A

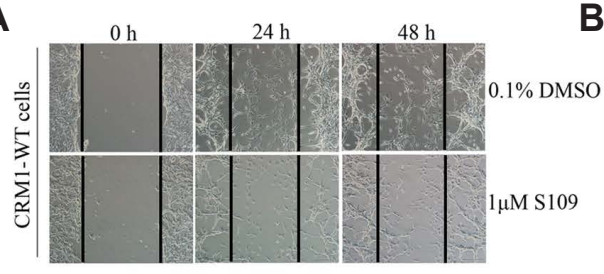

$0 \mathrm{~h}$

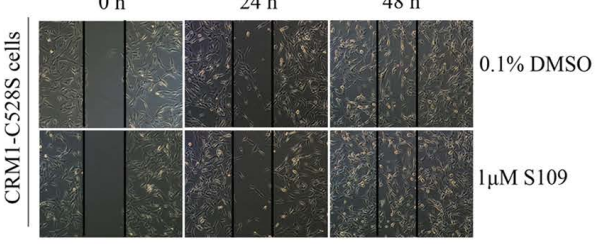

B

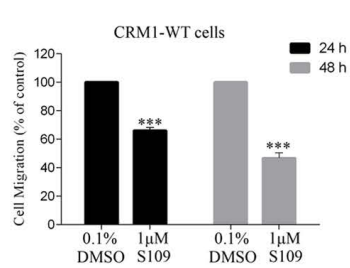

CRM1-C528S cells $24 \mathrm{~h}$

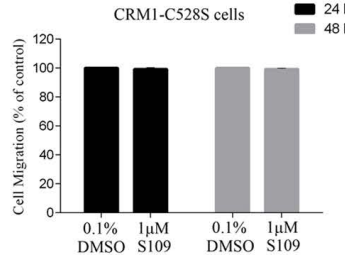

C

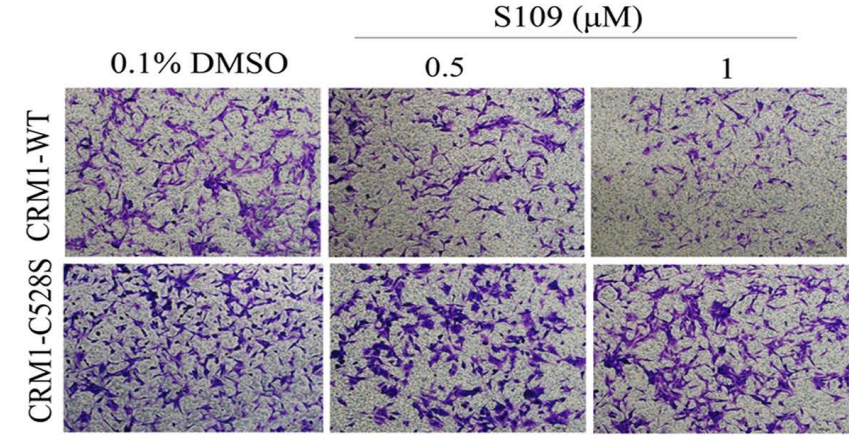

D

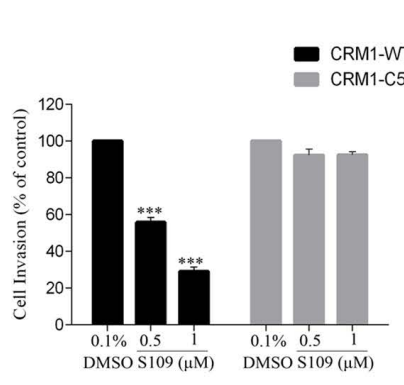

E

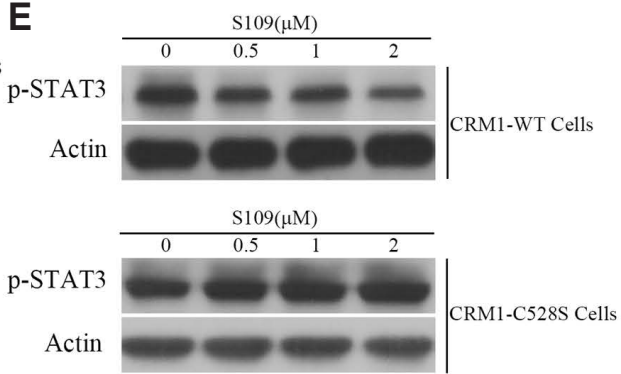

Fig. 4. The mutation of chromosomal region maintenance 1 (CRM1) C528 abolished the anti-migration and anti-invasion activity of S109 in glioma cells. U87 cells expressing wild-type (WT) and C528S-mutant CRM1 were treated with S109, and then migration and invasion were assessed by wound-healing cell migration assay $(A, B)$ and transwell invasion assay $(C, D)$. Results are expressed as means \pm standard error of the mean of three independent experiments. ${ }^{* * *} \mathrm{p}<0.001$ compared with the control group. The invasive cells were stained with a $0.1 \%$ crystal violet solution for 30 min. (E) The effect of S109 treatment on p-STAT3 expression level in CRM1-WT and CRM1-C528S cells. U87, U87-CRM1-WT and U87-CRM1-C528S cells were treated with $\mathrm{S} 109(0-2 \mu \mathrm{M})$ for $24 \mathrm{~h}$ respectively, and then the total protein was exacted. The expression level of p-STAT3 were examined by Western blot assays.

brain tumor [1], and the high recurrence rate and mortality are attributed to the highly invasive nature of these tumor cells [37]. Therefore, pharmacological suppression of glioma cell migration and invasion may be deemed a promising strategy for glioma treatment. Here, we found that the CRM1 inhibitor S109 effectively inhibited the migration and invasion of human glioma cells in vitro. Furthermore, our data suggested that S109 exerts its anti-migrative and anti-invasive activities through inactivation of the STAT3/MMP2 pathway. Overexpression of CRM1 has been identified in several types of malignant tumors and is associated with aggressive behavior and poor survival [38]. Therefore, CRM1 is considered a promising therapeutic target for gliomas.
Our previous study demonstrated that the CRM1 inhibitor S109 significantly suppressed the proliferation of glioma cells both in vitro and in vivo and prolonged the survival of nude mice [12]. In the present study, we found that S109 treatment significantly decreased the migrative and invasive ability of glioma cells. Previous reports have shown that CRM1 can bind to a hydrophobic nuclear export signal (NES) peptide of cargo substrate. The hydrophobic NES of the cargo protein binds to a hydrophobic groove of CRM1 containing an active site Cys528. CRM1 inhibitors bind to the active site Cys528 in CRM1 and site-directed mutagenesis of Cys528 to Ser528 will prevent binding of CRM1 by LMB and other CRM1 inhibitors [15,39]. In our study, we also 
found that mutation of CRM1 abolished the anti-invasive effect of S109. These data imply that CRM1 also plays an important role in the migration and invasion of glioma cells.

The migration of tumor cells across tissue barriers demands the degradation of specific components of the extracellular matrix [40]. ECM components confer cell migrative and invasive properties, prevent apoptosis and senescence, and contribute to immunosuppression [41]. MMP2 is a member of the extracellular matrix-degrading enzyme family, which is closely related to the invasion and migration of tumors, and plays an important role in matrix remodeling, angiogenesis, invasion, and tumor metastasis [42]. MMP2 is considered a diagnostic and prognostic biomarker and is also a potential therapeutic target [43]. CRM1-selective inhibitors can reduce migratory and invasive properties via suppressing the secretion and expression of MMP2 in prostate cancer cells [44]. Consistently, we found that S109 treatment resulted in a significant reduction in the levels of MMP2 protein. Further investigation demonstrated that S109 inhibited the activity of MMP2 in the U87 and U251 cells. These results suggest that S109 induced the inhibition of glioma cell migration and invasion by decreasing the activity and expression of MMP2.

STAT3 is constitutively activated in various cancers and is phosphorylated in the cytoplasm by growth factor receptors, Janus kinase, and Src kinase families $[45,46]$. The phosphorylated STAT3 forms homodimers and transfers into the nucleus, thereby regulating the transcription of target genes such as MMP2 [47]. Previous reports have suggested that STAT3 is persistently activated through constant nucleocytoplasmic shuttling, which is regulated by CRM1 $[48,49]$. STAT3 contains several NES elements through which it binds to CRM1 for nuclear export $[49,50]$. Inhibition of CRM1-mediated nuclear export can slow down the nucleocytoplasmic shuttling of activated STAT3 resulting in reduced tyrosine phosphorylation, decreased induction of STAT3 target genes, and increased apoptosis [51]. Previous studies have indicated that the STAT3/MMP2-involved pathway is significant to cancer invasion and metastasis [52]. In addition, STAT3 can promote the transcription of the target gene MMP2 via direct interaction with a consensus site in the MMP2 promoter [47]. Down-regulation of STAT3 phosphorylation leads to decreased MMP2 activity, migration, and invasion in human brain cancer cells [35]. Consistent with these studies, our results showed that S109 treatment decreased the level of STAT3 phosphorylation. Taken together, our data support that CRM1 inhibition by S109 decreases phosphorylation of STAT3, which in turn inhibits the expression and activity of MMP2. Ultimately, these processes lead to suppression of migration and invasion in glioma cells.

In summary, we elucidated that a novel CRM1 selective reversible inhibitor, S109, inhibited glioma cell migration and invasion by inactivation of the STAT3/MMP2 signaling pathway. However, further in-depth studies are needed to confirm how S109 regulates STAT3 activity. Based on the evidence provided here, our data suggest that S109 may act as an effective chemotherapeutic drug for the treatment of gliomas.

\section{ACKNOWLEDGEMENTS}

The research was supported by National Natural Science Foundation of China (No. 81772658, 81670142, 81972345); Jiangsu Provincial Key Research and Development Program (BE2017636, BE2017638); Natural Science Foundation of Jiangsu Province (BK20180104); The Foundation of Jiangsu Province Six Talents Peak (No. 2016-WSN-136, No. 2017-WSN-120); Jiangsu Qing Lan Project for Mingshan Niu.

\section{CONFLICTS OF INTEREST}

The authors declare no conflicts of interest.

\section{SUPPLEMENTARY MATERIALS}

Supplementary data including two figures and one table can be found with this article online at http://pdf.medrang.co.kr/paper/ pdf/Kjpp/Kjpp2020-24-03-01-s001.pdf.

\section{REFERENCES}

1. Piromkraipak P, Sangpairoj K, Tirakotai W, Chaithirayanon K, Unchern S, Supavilai P, Power C, Vivithanaporn P. Cysteinyl leukotriene receptor antagonists inhibit migration, invasion, and expression of MMP-2/9 in human glioblastoma. Cell Mol Neurobiol. 2018;38:559-573.

2. Mu N, Gu J, Liu N, Xue X, Shu Z, Zhang K, Huang T, Chu C, Zhang W, Gong L, Zhao H, Jia B, Gao D, Shang L, Zhang W, Guo Q. PRL-3 is a potential glioblastoma prognostic marker and promotes glioblastoma progression by enhancing MMP7 through the ERK and JNK pathways. Theranostics. 2018;8:1527-1539.

3. Liu YP, Dong FX, Chai X, Zhu S, Zhang BL, Gao DS. Role of autophagy in capsaicin-induced apoptosis in U251 glioma cells. Cell Mol Neurobiol. 2016;36:737-743.

4. Zhang BL, Liu J, Lei Y, Xiong Y, Li H, Lin X, Yao RQ, Gao DS. An epigenetic mechanism of high gdnf transcription in glioma cells revealed by specific sequence methylation. Mol Neurobiol. 2016; 53:4352-4362.

5. García-Santisteban I, Arregi I, Alonso-Mariño M, Urbaneja MA, Garcia-Vallejo JJ, Bañuelos S, Rodríguez JA. A cellular reporter to evaluate CRM1 nuclear export activity: functional analysis of the cancer-related mutant E571K. Cell Mol Life Sci. 2016;73:4685-4699.

6. Noske A, Weichert W, Niesporek S, Röske A, Buckendahl AC, Koch I, Sehouli J, Dietel M, Denkert C. Expression of the nuclear export protein chromosomal region maintenance/exportin 1/Xpol is a prognostic factor in human ovarian cancer. Cancer. 2008;112:17331743. 
7. Tajiri N, De La Peña I, Acosta SA, Kaneko Y, Tamir S, Landesman Y, Carlson R, Shacham S, Borlongan CV. A nuclear attack on traumatic brain injury: sequestration of cell death in the nucleus. CNS Neurosci Ther. 2016;22:306-315.

8. Wang H, Ding Z, Shi QM, Ge X, Wang HX, Li MX, Chen G, Wang Q, Ju Q, Zhang JP, Zhang MR, Xu LC. Anti-androgenic mechanisms of Bisphenol A involve androgen receptor signaling pathway. Toxicology. 2017;387:10-16.

9. Zhou F, Chen E, You D, Song Y, Sun Z, Yue L. Both high expression of nucleophosmin/B23 and CRM1 predicts poorer prognosis in human gastric cancer. APMIS. 2016;124:1046-1053.

10. Li C, Yang D, Cao X, Wang F, Jiang H, Guo H, Du L, Guo Q, Yin X. LFG-500, a newly synthesized flavonoid, attenuates lipopolysaccharide-induced acute lung injury and inflammation in mice. Biochem Pharmacol. 2016;113:57-69.

11. Yao Y, Dong Y, Lin F, Zhao H, Shen Z, Chen P, Sun YJ, Tang LN, Zheng SE. The expression of CRM1 is associated with prognosis in human osteosarcoma. Oncol Rep. 2009;21:229-235.

12. Liu X, Chong Y, Tu Y, Liu N, Yue C, Qi Z, Liu H, Yao Y, Liu H, Gao $\mathrm{S}$, Niu M, Yu R. CRM1/XPO1 is associated with clinical outcome in glioma and represents a therapeutic target by perturbing multiple core pathways. J Hematol Oncol. 2016;9:108.

13. Yang X, Cheng L, Yao L, Ren H, Zhang S, Min X, Chen X, Zhang J, Li M. Involvement of chromosome region maintenance 1 (CRM1) in the formation and progression of esophageal squamous cell carcinoma. Med Oncol. 2014;31:155.

14. Dickmanns A, Monecke T, Ficner R. Structural basis of targeting the exportin CRM1 in cancer. Cells. 2015;4:538-568.

15. Turner JG, Dawson J, Cubitt CL, Baz R, Sullivan DM. Inhibition of CRM1-dependent nuclear export sensitizes malignant cells to cytotoxic and targeted agents. Semin Cancer Biol. 2014;27:62-73.

16. Paulus A, Ailawadhi S, Chanan-Khan A. Novel therapeutic targets in Waldenstrom macroglobulinemia. Best Pract Res Clin Haematol. 2016;29:216-228.

17. Fathi N, Rashidi G, Khodadadi A, Shahi S, Sharifi S. STAT3 and apoptosis challenges in cancer. Int J Biol Macromol. 2018;117:9931001.

18. Jiang C, Xu Q, Xu K, Dai H, Zhang Z, Wu W, Ni J. Effects of erythropoietin on STAT1 and STAT3 levels following cerebral ischemiareperfusion in rats. Int J Neurosci. 2013;123:684-690.

19. Zheng T, Hong X, Wang J, Pei T, Liang Y, Yin D, Song R, Song X, Lu Z, Qi S, Liu J, Sun B, Xie C, Pan S, Li Y, Luo X, Li S, Fang X, Bhatta $\mathrm{N}$, Jiang $\mathrm{H}$, et al. Gankyrin promotes tumor growth and metastasis through activation of IL-6/STAT3 signaling in human cholangiocarcinoma. Hepatology. 2014;59:935-946.

20. De Simone V, Franzè E, Ronchetti G, Colantoni A, Fantini MC, Di Fusco D, Sica GS, Sileri P, MacDonald TT, Pallone F, Monteleone G, Stolfi C. Th17-type cytokines, IL-6 and TNF- $\alpha$ synergistically activate STAT3 and NF-kB to promote colorectal cancer cell growth. Oncogene. 2015;34:3493-3503.

21. Wang YC, Zheng LH, Ma BA, Zhou Y, Zhang MH, Zhang DZ, Fan QY. Clinical value of signal transducers and activators of transcription 3 (STAT3) gene expression in human osteosarcoma. Acta Histochem. 2011;113:402-408.

22. Zhao C, Li H, Lin HJ, Yang S, Lin J, Liang G. Feedback activation of STAT3 as a cancer drug-resistance mechanism. Trends Pharmacol Sci. 2016;37:47-61.
23. Senft C, Priester M, Polacin M, Schröder K, Seifert V, Kögel D, Weissenberger J. Inhibition of the JAK-2/STAT3 signaling pathway impedes the migratory and invasive potential of human glioblastoma cells. J Neurooncol. 2011;101:393-403.

24. Nusblat LM, Carroll MJ, Roth CM. Crosstalk between M2 macrophages and glioma stem cells. Cell Oncol (Dordr). 2017;40:471-482.

25. Liu X, Chen X, Shi L, Shan Q, Cao Q, Yue C, Li H, Li S, Wang J, Gao S, Niu M, Yu R. The third-generation EGFR inhibitor AZD9291 overcomes primary resistance by continuously blocking ERK signaling in glioblastoma. J Exp Clin Cancer Res. 2019;38:219.

26. Han ZX, Wang XX, Zhang SN, Wu JX, Qian HY, Wen YY, Tian H, Pei DS, Zheng JN. Downregulation of PAK5 inhibits glioma cell migration and invasion potentially through the PAK5-Egrl-MMP2 signaling pathway. Brain Tumor Pathol. 2014;31:234-241.

27. Fan YC, Mei PJ, Chen C, Miao FA, Zhang H, Li ZL. MiR-29c inhibits glioma cell proliferation, migration, invasion and angiogenesis. $J$ Neurooncol. 2013;115:179-188.

28. Mei PJ, Bai J, Miao FA, Li ZL, Chen C, Zheng JN, Fan YC. Relationship between expression of XRCC1 and tumor proliferation, migration, invasion, and angiogenesis in glioma. Invest New Drugs. 2019;37:646-657.

29. Yue C, Niu M, Shan QQ, Zhou T, Tu Y, Xie P, Hua L, Yu R, Liu X. High expression of Bruton's tyrosine kinase (BTK) is required for EGFR-induced NF- $\mathrm{kB}$ activation and predicts poor prognosis in human glioma. J Exp Clin Cancer Res. 2017;36:132.

30. Teng DC, Sun J, An YQ, Hu ZH, Liu P, Ma YC, Han B, Shi Y. Role of PHLPP1 in inflammation response: Its loss contributes to gliomas development and progression. Int Immunopharmacol. 2016;34:229234.

31. Liu F, Zhao X, Qian Y, Zhang J, Zhang Y, Yin R. MiR-206 inhibits Head and neck squamous cell carcinoma cell progression by targeting HDAC6 via PTEN/AKT/mTOR pathway. Biomed Pharmacother. 2017;96:229-237.

32. Falk P, Jonsson A, Swartling T, Asplund D, Ivarsson ML. Role of matrix metalloproteinases in tumour invasion: immunohistochemistry of peritoneum from peritoneal carcinomatosis. Med Oncol. 2018;35:64.

33. Yang Q, Wang WW, Ma P, Ma ZX, Hao M, Adelusi TI, Lei-Du, Yin $\mathrm{XX}, \mathrm{Lu} \mathrm{Q}$. Swimming training alleviated insulin resistance through Wnt3a/ $\beta$-catenin signaling in type 2 diabetic rats. Iran J Basic Med Sci. 2017;20:1220-1226.

34. Chen F, Xu Y, Luo Y, Zheng D, Song Y, Yu K, Li H, Zhang L, Zhong W, Ji Y. Down-regulation of Stat 3 decreases invasion activity and induces apoptosis of human glioma cells. J Mol Neurosci. 2010;40:353359.

35. Cho HJ, Park JH, Nam JH, Chang YC, Park B, Hoe HS. Ascochlorin suppresses MMP-2-mediated migration and invasion by targeting FAK and JAK-STAT signaling cascades. J Cell Biochem. 2018;119:300-313.

36. Sun Q, Carrasco YP, Hu Y, Guo X, Mirzaei H, Macmillan J, Chook YM. Nuclear export inhibition through covalent conjugation and hydrolysis of Leptomycin B by CRM1. Proc Natl Acad Sci U S A. 2013;110:1303-1308.

37. Lu DY, Yeh WL, Huang SM, Tang CH, Lin HY, Chou SJ. Osteopontin increases heme oxygenase-1 expression and subsequently induces cell migration and invasion in glioma cells. Neuro Oncol. 2012;14:1367-1378. 
38. Ishizawa J, Kojima K, Hail N Jr, Tabe Y, Andreeff M. Expression, function, and targeting of the nuclear exporter chromosome region maintenance 1 (CRM1) protein. Pharmacol Ther. 2015;153:25-35.

39. Sakakibara K, Saito N, Sato T, Suzuki A, Hasegawa Y, Friedman JM, Kufe DW, Vonhoff DD, Iwami T, Kawabe T. CBS9106 is a novel reversible oral CRM1 inhibitor with CRM1 degrading activity. Blood. 2011;118:3922-3931.

40. Li WX, Yang MX, Hong XQ, Dong TG, Yi T, Lin SL, Qin XY, Niu WX. Overexpression of gelsolin reduces the proliferation and invasion of colon carcinoma cells. Mol Med Rep. 2016;14:3059-3065.

41. Friedl P, Alexander S. Cancer invasion and the microenvironment: plasticity and reciprocity. Cell. 2011;147:992-1009.

42. Panth KM, van den Beucken T, Biemans R, Lieuwes NG, Weber M, Losen M, Yaromina A, Dubois LJ, Lambin P. In vivo optical imaging of MMP2 immuno protein antibody: tumor uptake is associated with MMP2 activity. Sci Rep. 2016;6:22198.

43. Yu Q, Shen W, Zhou H, Dong W, Gao D. Knockdown of LIcadherin alters expression of matrix metalloproteinase-2 and -9 and galectin-3. Mol Med Rep. 2016;13:4469-4474.

44. Gravina GL, Tortoreto M, Mancini A, Addis A, Di Cesare E, Lenzi A, Landesman Y, McCauley D, Kauffman M, Shacham S, Zaffaroni N, Festuccia C. XPO1/CRM1-selective inhibitors of nuclear export (SINE) reduce tumor spreading and improve overall survival in preclinical models of prostate cancer (PCa). J Hematol Oncol. 2014;7: 46.

45. Yu H, Kortylewski M, Pardoll D. Crosstalk between cancer and immune cells: role of STAT3 in the tumour microenvironment. Nat Rev Immunol. 2007;7:41-51.
46. Sato N, Tsuruma R, Imoto S, Sekine Y, Muromoto R, Sugiyama K, Matsuda T. Nuclear retention of STAT3 through the coiledcoil domain regulates its activity. Biochem Biophys Res Commun. 2005;336:617-624.

47. Ou Y, Liu L, Xue L, Zhou W, Zhao Z, Xu B, Song Y, Zhan Q. TRAP1 shows clinical significance and promotes cellular migration and invasion through STAT3/MMP2 pathway in human esophageal squamous cell cancer. J Genet Genomics. 2014;41:529-537.

48. Herrmann A, Vogt M, Mönnigmann M, Clahsen T, Sommer U, Haan S, Poli V, Heinrich PC, Müller-Newen G. Nucleocytoplasmic shuttling of persistently activated STAT3. J Cell Sci. 2007;120(Pt 18): 3249-3261.

49. Bhattacharya S, Schindler C. Regulation of Stat 3 nuclear export. $J$ Clin Invest. 2003;111:553-559.

50. Shao WY, Yang YL, Yan H, Huang Q, Liu KJ, Zhang S. Phenethyl isothiocyanate suppresses the metastasis of ovarian cancer associated with the inhibition of CRM1-mediated nuclear export and mTOR-STAT3 pathway. Cancer Biol Ther. 2017;18:26-35.

51. Cheng Y, Holloway MP, Nguyen K, McCauley D, Landesman Y, Kauffman MG, Shacham S, Altura RA. XPO1 (CRM1) inhibition represses STAT3 activation to drive a survivin-dependent oncogenic switch in triple-negative breast cancer. Mol Cancer Ther. 2014;13: 675-686.

52. Xie TX, Wei D, Liu M, Gao AC, Ali-Osman F, Sawaya R, Huang S. Stat 3 activation regulates the expression of matrix metalloproteinase-2 and tumor invasion and metastasis. Oncogene. 2004;23:35503560 . 